\title{
Cortex Moutan Induces Bladder Cancer Cell Death via Apoptosis and Retards Tumor Growth in Mouse Bladders
}

\author{
Mei-Yi Lin, ${ }^{1,2}$ Ying-Ray Lee, ${ }^{3,4}$ Su-Yin Chiang, ${ }^{1}$ Yi-Zhen Li, ${ }^{5}$ Yueh-Sheng Chen, ${ }^{1,6}$ \\ Cheng-Da Hsu, ${ }^{3}$ and Yi-Wen Liu ${ }^{5}$ \\ ${ }^{1}$ Graduate Institute of Chinese Medicine, College of Chinese Medicine, China Medical University, Taichung 40402, Taiwan \\ ${ }^{2}$ Department of Chinese Medicine, Chiayi Christian Hospital, Chiayi 60002, Taiwan \\ ${ }^{3}$ Department of Medical Research, Chiayi Christian Hospital, Chiayi 60002, Taiwan \\ ${ }^{4}$ Department of Nursing, Min-Hwei College of Health Care Management, Tainan 73658, Taiwan \\ ${ }^{5}$ Department of Microbiology, Immunology and Biopharmaceuticals, College of Life Sciences, National Chiayi University, \\ No. 300, Syuefu Road, Chiayi 60004, Taiwan \\ ${ }^{6}$ Department of Biomedical Imaging and Radiological Science, China Medical University, Taichung 40402, Taiwan
}

Correspondence should be addressed to Yi-Wen Liu; ywlss@mail.ncyu.edu.tw

Received 28 March 2013; Accepted 5 September 2013

Academic Editor: Cheorl-Ho Kim

Copyright (C) 2013 Mei-Yi Lin et al. This is an open access article distributed under the Creative Commons Attribution License, which permits unrestricted use, distribution, and reproduction in any medium, provided the original work is properly cited.

Cortex Moutan is the root bark of Paeonia suffruticosa Andr. It is the herbal medicine widely used in Traditional Chinese Medicine for the treatment of blood-heat and blood-stasis syndrome. Furthermore, it has been reported that Cortex Moutan has anticancer effect. In this study, the Cortex Moutan extract was evaluated in bladder cancer therapy in vitro and in vivo. Cortex Moutan extract reduces cell viability with $\mathrm{IC}_{50}$ between $1 \sim 2 \mathrm{mg} / \mathrm{ml}$ in bladder cancer cells, and it has lower cytotoxicity in normal urotheliums. It arrests cells in G1 and S phase and causes phosphatidylserine expression in the outside of cell membrane. It induces caspase- 8 and caspase- 3 activation and poly(ADP-ribose) polymerase degradation. The pan caspase inhibitor z-VAD-fmk reverses Cortex Moutan-induced cell death. Cortex Moutan also inhibits cell invasion activity in 5637 cells. In mouse orthotopic bladder cancer model, intravesical application of Cortex Moutan decreases the bladder tumor size without altering the blood biochemical parameters. In summary, these results demonstrate the antiproliferation and anti-invasion properties of Cortex Moutan in bladder cancer cells and its antibladder tumor effect in vivo. Cortex Moutan may provide an alternative therapeutic strategy for the intravesical therapy of superficial bladder cancer.

\section{Introduction}

Cortex Moutan (CM, root bark of Paeonia suffruticosa Andr.), named Mu Dan Pi in Chinese, is the herbal medicine widely used in Traditional Chinese Medicine (TCM). It tastes bitter and pungent. According to TCM theory, it belongs to the light cold-type medicine and has the function of heat-clearing, promoting blood circulation, removing blood stasis, cooling the blood, and reducing the deficient heat. In clinical regimen, CM is usually used to treat heat in the blood and blood stasis syndromes. It is used as an analgesic [1], antispasmodic, antiaggregatory $[2,3]$, and antioxidative agent [4]. In other reports, CM itself or its major component has been shown to treat various disorders like diabetes [5], Alzheimer's disease
$[6,7]$, arthritis [8], inflammation $[9,10]$, sepsis [11], brain ischemia-reperfusion injury [12], HIV infection [13], and herpes simplex virus infection [14]. Recently, there are also some reports showing the anitumor activity of $\mathrm{CM}$, including renal carcinoma [15], DLD-1 human colon cancer cells [16], and gastric cancer [17]. In addition, one component of CM, paeoniflorin, was reported to have antitumor effect through apoptosis in lung cancer cells [18].

Bladder cancer is a common malignancy worldwide [19]. A person with the history of urinary tract cancer in firstdegree relatives and heavy cigarette smoking increases the risk of bladder cancer [20]. More than $90 \%$ of bladder cancers are transitional cell carcinoma (TCC) in the histology, and it is classified into two groups in the pathogenesis: nonmuscle 
invasive and muscle invasive [21]. There are two groups of intravesical therapeutic agents for bladder cancer therapy. Bacillus Calmette-Guérin (BCG) is the immunotherapeutic agent, and mitomycin $\mathrm{C}$ is one of the chemotherapeutic agents $[21,22]$. Up to now, BCG provokes considerable and sometimes serious side effects, and the recurrence rate remains high in spite of intravesical chemotherapy. There is certainly place for improvement in bladder cancer therapy. Intravesical antitumor herbal medicine may provide an alternative pathway in the treatment of TCC.

The antitumor effect of CM extract on bladder cancer is still unknown. In this study, we investigated the anticancer effect of CM extract in two bladder cancer cell lines and the in vivo effect in a mouse orthotopic bladder tumor model.

\section{Materials and Methods}

2.1. Cell Culture and CM Extract Preparation. Human bladder papillary transitional cell carcinoma 5637 cells were obtained from the Bioresource Collection and Research Center (Hsinchu, Taiwan). Mouse bladder carcinoma MB49 cells were kindly provided by Dr. Timonthy L. Ratliff (Purdue Cancer Center, West Lafayette, IN). 5637 and MB49 cells were maintained in RPMI 1640 medium supplied with $10 \%$ fetal bovine serum (FBS), $1 \%$ penicillin, and $1 \%$ streptomycin. Cells were incubated in a $\mathrm{CO}_{2}$ incubator at $37^{\circ} \mathrm{C}$, with $5 \%$ $\mathrm{CO}_{2}$ and $95 \%$ filtered air. $\mathrm{CM}$ powder was purchased from Sun Ten Pharmaceutical Co., Ltd. (Taipei, Taiwan). CM extract was prepared by mixing CM powder with RPMI 1640 medium $(50 \mathrm{mg} / \mathrm{mL})$, sonicated on ice for $60 \mathrm{~min}$, filtered by the qualitative filter paper, $0.45 \mu \mathrm{m}$ filter and $0.2 \mu \mathrm{m}$ filter, then stocked at $-80^{\circ} \mathrm{C}$ before use. The stock concentration is $50 \mathrm{mg} / \mathrm{mL}$, and RPMI 1640 medium is used for dilution.

2.2. Reagents and Antibodies. Propidium iodide (PI), ribonuclease A (RNase A), z-VAD-fmk, and formaldehyde were purchased from Sigma (St. Louis, MO, USA). Annexin V-FITC apoptosis detection kit was purchased from Strong Biotech Corporation (Taipei, Taiwan). Antibodies against caspase8 (D35G2), cleaved caspase-3 (Asp175), and poly(ADPribose) polymerase (PARP) were purchased from Cell Signaling (Danvers, MA, USA). Anti-glyceraldehyde-3-phosphate dehydrogenase (GAPDH) antibody was purchased from GeneTex (Taichung, Taiwan). The Millicell Hanging Cell Culture Inserts of Transwell system was purchased from Millipore (Billerica, MA, USA).

2.3. Cell Viability Assay. Cell number was determined by direct cell counting. MB49 $\left(4 \times 10^{4}\right.$ cells/well $)$ or $5637(5 \times$ $10^{4}$ cells/well) cells were cultured in 24-well plates; SV-HUC1 cells $\left(2 \times 10^{4}\right.$ cells/well) were cultured in 96-well plate. After $24 \mathrm{~h}$, cells were incubated with various concentrations of CM extract for another 24 and $48 \mathrm{~h}$. The cells were detached by trypsin treatment, trypan blue staining, and counted by a haemocytometer. The result was expressed as a percentage, relative to control group.

2.4. Cell Cycle Analysis. MB49 $\left(1 \times 10^{6}\right.$ cells/dish $)$ or 5637 $\left(2 \times 10^{6}\right.$ cells/dish $)$ cells were seeded in $100 \mathrm{~mm}$ dishes.
After $24 \mathrm{~h}$ incubation for attachment, CM extract was added. After treatment for $24 \mathrm{~h}$ and $48 \mathrm{~h}$, cells were trypsinized, centrifuged, and fixed with ice-cold $75 \%$ ethanol overnight at $4^{\circ} \mathrm{C}$. After removing the ethanol, cells were stained with a DNA staining solution (containing $1 \mathrm{mg} / \mathrm{mL}$ PI and $10 \mathrm{mg} / \mathrm{mL}$ RNase A dissolved in PBS) for $30 \mathrm{~min}$ at room temperature. The DNA content of the stained cells was measured using a FACScan flow cytometer. The cell doublets were removed by gating the left area of FL2-W/FL2-A plot for analysis. Cell cycle data from flow cytometry was analyzed using ModFit LT software which distinguished cell cycle to G1 (2n), S (between $2 n$ to $4 \mathrm{n}$ ), G2/M (4n), and sub G1 (debris) according to DNA content in a single cell.

2.5. Apoptotic Cell Death Analysis. MB49 $\left(1 \times 10^{6}\right.$ cells/dish $)$ or $5637\left(2 \times 10^{6}\right.$ cells/dish $)$ cells were seeded in $100 \mathrm{~mm}$ dishes. After $24 \mathrm{~h}, \mathrm{CM}$ extract was added. After treatment for $24 \mathrm{~h}$ and $48 \mathrm{~h}$, cells were collected after washing, trypsinization, and centrifugation. The cell pellets were resuspended in $100 \mu \mathrm{L}$ of staining solution $(2 \mu \mathrm{L}$ Annexin-V-FITC and $2 \mu \mathrm{L}$ PI in $100 \mu \mathrm{L}$ binding buffer) and incubated for $15 \mathrm{~min}$ at room temperature. Annexin-V or PI fluorescent intensities were analyzed by a FACScan flow cytometer.

2.6. Cell Invasion Assay. The invasion assay was analyzed using a Matrigel- (BD Biosciences) coated Transwell system (Millipore). The upper chamber of the transwell was coated with $25 \mu \mathrm{g}$ Matrigel. 5637 cells $\left(1 \times 10^{5}\right)$ in serum-free RPMI1640 media were seeded onto Matrigel-coated Transwell. CM extract was added into upper and lower chamber media. In the lower chambers, $10 \%$ FBS was added as a chemoattractant. After a $24 \mathrm{~h}$ incubation time, the cells that remained on the upper surface of the filter membrane were removed, and the cells on the opposite surface of the filter membrane were fixed with $4 \%$ formaldehyde for $30 \mathrm{~s}$, stained with crystal violet and photographed under microscopy at 200x magnification. The number of migrated cells was counted in five randomly chosen microscope fields.

2.7. Mouse Orthotopic Bladder Tumor Model. The female C57BL/6 mice aged six weeks were provided by the National Laboratory Animal Center (Taipei, Taiwan) and maintained at our animal care facility for one week prior to use. The implantation of mouse bladder cancer cells MB49 into C57BL/6 mice was carried out similarly as previous reports [23-25]. After MB49 inoculation (Day 1), mice were randomly assigned to two groups (8 mice/group). One group was intravesically treated with RPMI 1640 medium, and the other group received $2.5 \mathrm{mg} /$ mouse CM extract intravesically every other day from Day 16 to 24 . At the 26 th day, the mice were sacrificed, and the bladder volumes were measured before formalin fixation. After cutting the paraffinembedded bladder tissues into $4 \mu \mathrm{m}$ sections, the slides of each mouse bladder were confirmed under a microscope in histology by hematoxylin and eosin staining. The experiment was approved by the Institutional Animal Care and Use Committee of National Chiayi University. 


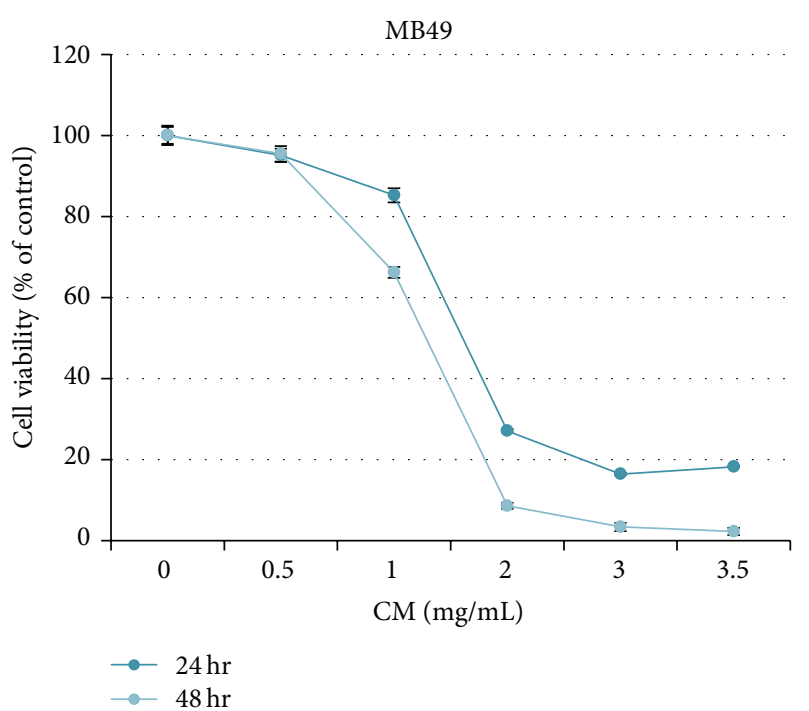

(a)

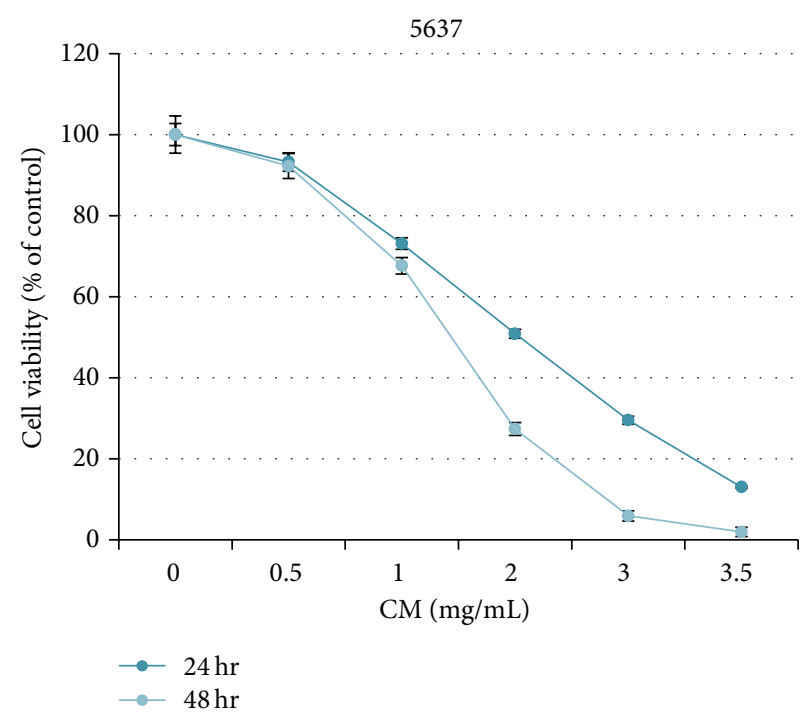

(b)

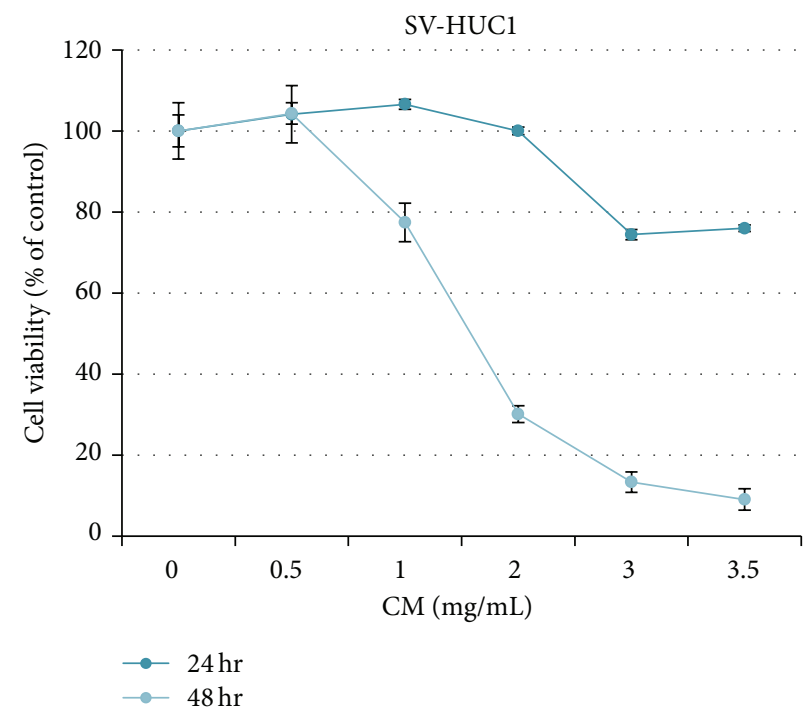

(c)

FIgURE 1: The cytotoxicity of CM extract in bladder cancer cells and normal urotheliums. The cytotoxicity was analyzed after CM treatment for $24 \mathrm{~h}$ and $48 \mathrm{~h}$. The cell number of control was regarded as $100 \%$. Data represent the mean \pm SEM of quadruplicate. The experiment was repeated for three times.

2.8. Statistical Analysis. The values shown are mean \pm SEM. Data are statistically evaluated by one way ANOVA and shown significantly different in ${ }^{*} P<0.05,{ }^{* *} P<0.01$, and ${ }^{* * *} P<0.001$.

\section{Results}

3.1. Cytotoxicity of CM Extract in MB49, 5637, and SV-HUC1 Cells. In mouse bladder cancer cells $\mathrm{MB} 49$, the $\mathrm{IC}_{50}$ of $\mathrm{CM}$ extract is $1.3 \mathrm{mg} / \mathrm{mL}$ at $48 \mathrm{~h}$ treatment and $1.6 \mathrm{mg} / \mathrm{mL}$ at $24 \mathrm{~h}$ (Figure 1(a)). In human bladder cancer cell 5637, the $\mathrm{IC}_{50}$ of CM extract is $1.4 \mathrm{mg} / \mathrm{mL}$ and $2.0 \mathrm{mg} / \mathrm{mL}$ at $48 \mathrm{~h}$ and $24 \mathrm{~h}$ treatment, respectively (Figure $1(\mathrm{~b})$ ). In human normal urothelium SV-HUC1 cells, the $\mathrm{IC}_{50}$ is $1.6 \mathrm{mg} / \mathrm{mL}$ at $48 \mathrm{~h}$, but it is higher than $3.5 \mathrm{mg} / \mathrm{mL}$ at $24 \mathrm{~h}$ (Figure 1(c)). According to these data, CM extract shows a good anticancer effect and a minor damage to normal cells at $24 \mathrm{~h}$ treatment.

3.2. CM Extract Induces Apoptotic Cell Death. Cell cycle analysis was performed in MB49 and 5637 cells after CM extract treatment. CM dose dependently increased subG1 population while decreasing G1 and S population in MB49 and 5637 cells (Figure 2(a)). CM also increased exposed phosphatidylserine by Annex V-FITC staining assay in MB49 and 5637 cells (Figure 2(b)). The CM-induced apoptosis was also confirmed by Western Blot analysis. It 
MB49
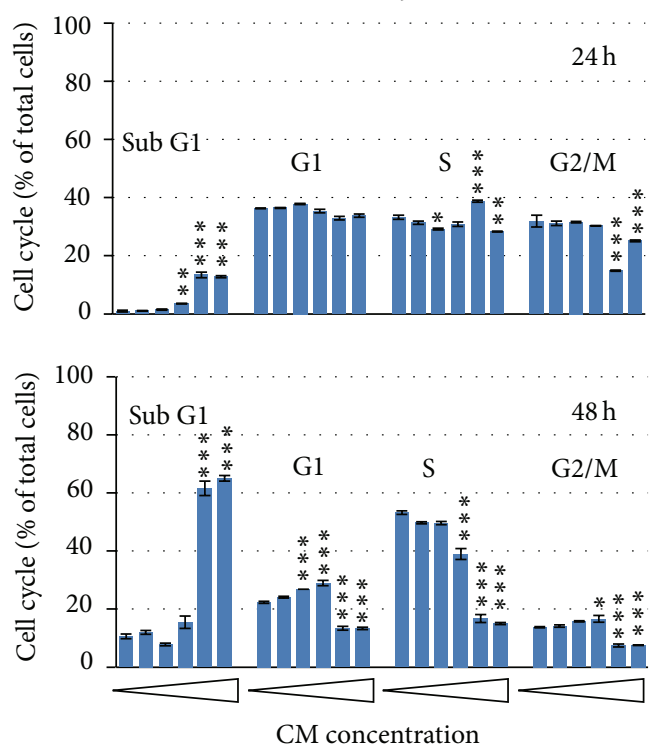

(a)
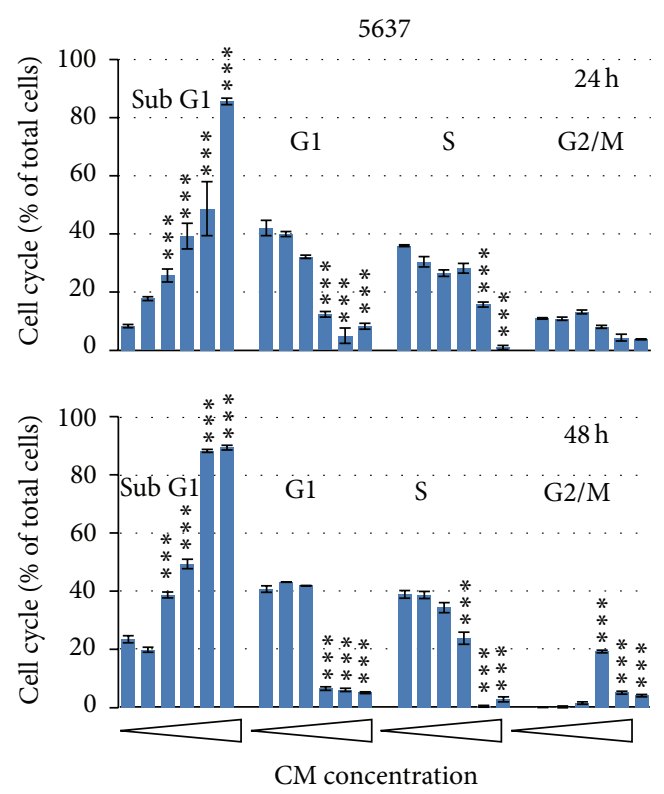

5637

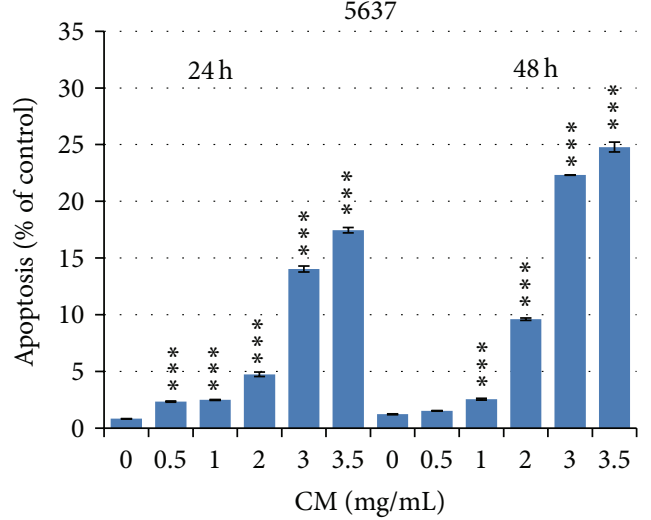

(b)
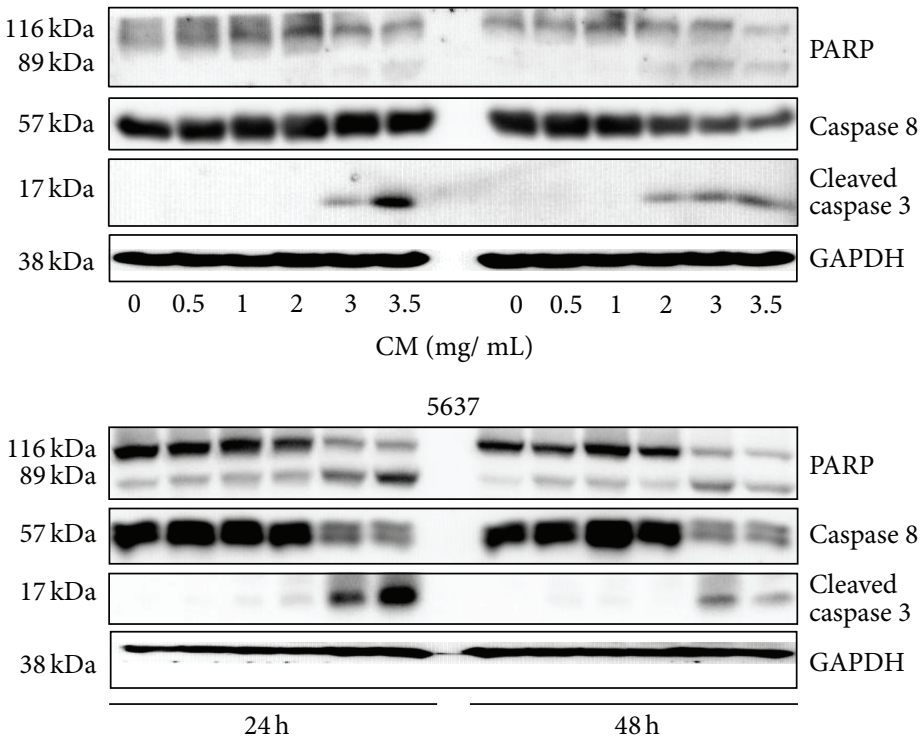

(c)

Figure 2: Continued. 

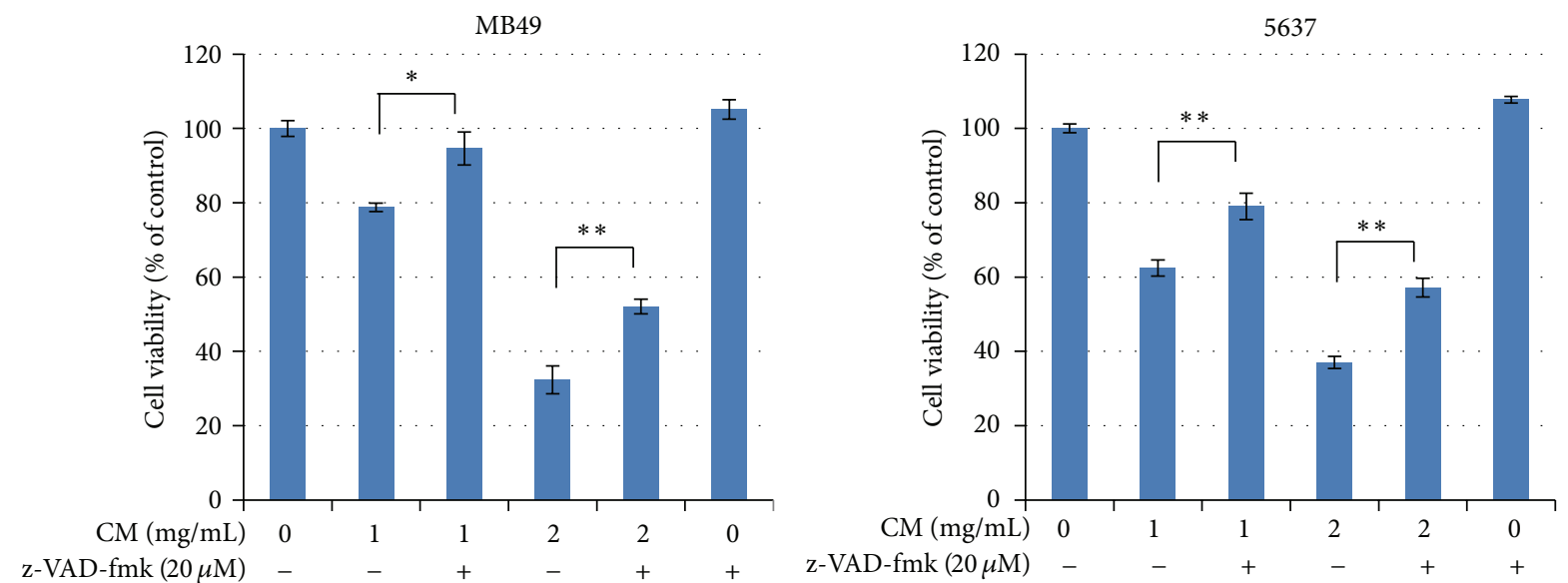

(d)

FIGURE 2: CM extract induces cell apoptosis. (a) Cell cycle distribution after CM treatment. Cells were treated with medium or CM extract $(0,0.5,1,2,3,3.5 \mathrm{mg} / \mathrm{mL})$ for $24 \mathrm{~h}$ and $48 \mathrm{~h}$ then collected for cell cycle analysis. Data represent the mean \pm SEM of triplicate. ${ }^{*} P<0.05$, ${ }^{* *} P<0.01$, and ${ }^{* * *} P<0.001$ compared with control. (b) Apoptosis analysis by Annexin-V-PI staining assay. The apoptosis percentage implied the Annexin-V-positive and PI-negative staining cells. Data represent the mean \pm SEM of triplicate. ${ }^{* * *} P<0.001$ compared with control. (c) Western blot analysis of apoptotic proteins including PARP (original $116 \mathrm{kDa}$ and degraded $89 \mathrm{kDa}$ forms), original caspase-8, activated caspcas-3, and GAPDH (internal control). (d) z-VAD-fmk reverses CM-induced cell death. $\mathrm{z}$-VAD-fmk was added in medium $1 \mathrm{~h}$ before CM treatment, and cell number was counted after CM treatment for $24 \mathrm{~h}$. Data represent the mean \pm SEM of quadruplicate. ${ }^{*} P<0.05$, and ${ }^{* *} P<0.01$ compared with each other. All the experiments were repeated for three times.

shows that $\mathrm{CM}$ dose dependently induces the activation of caspase-8 and caspase-3, and degrades PARP in MB49 and 5637 cells (Figure 2(c)). When the pan-caspase inhibitor $\mathrm{z}$-VAD-fmk was added, it partially reversed CM-induced cell death (Figure $2(\mathrm{~d})$ ). These results suggest that CM induces cell death at least via extrinsic apoptosis pathway, which was concurrent with the activation of caspase- 8 and caspase-3.

3.3. CM Extract Inhibits Cell Invasion in 5637 Cells. The cell invasion assay was analyzed by Matrigel-coated transwells. The invasive activity of 5637 cells is stronger than that of MB49 cells, so the assay is explored in 5637 cells only. The data indicates that CM extract dose dependently inhibits cell invasion, and the inhibition percentage is higher than that of cell growth at the same dose (Figure 3). It suggests that $\mathrm{CM}$ extract, besides cytotoxicity, also have anti-invasive activity.

3.4. CM Extract Inhibits Tumor Growth in a Mouse Orthotopic Bladder Tumor Model. After tumor implantation at Day 1, CM extract intravesical application was developed from Day 16 to Day 24 once two days. The body weights did not significantly change between control and CM-treated mice (Figure 4(a)). The bladder size was calculated after sacrifice at Day 26. Intravesical CM treatment significantly decreased bladder volume and retarded tumor invading into muscle layer (Figure 4(b)). In the blood biochemistry data, it shows no significant difference between 2 groups (Table 1). It suggests that intravesical CM treatment decreases bladder tumor size without adverse event in liver and kidney.
TABLe 1: The blood biochemical parameters after CM extract intravesical application. After sacrifice, the blood was collected for preparing serum which was provided for biochemical parameter analysis.

\begin{tabular}{lcc}
\hline Biochemical parameters & Control & CM \\
\hline BUN (mg/dL) & $25.50 \pm 1.22$ & $24.35 \pm 1.02$ \\
Creatine (mg/dL) & $0.56 \pm 0.03$ & $0.57 \pm 0.02$ \\
SGOT (U/L) & $192.93 \pm 51.97$ & $217.90 \pm 28.91$ \\
SGPT (U/L) & $28.0 \pm 2.75$ & $28.87 \pm 2.20$ \\
\hline
\end{tabular}

Data represent the mean \pm SEM. There are no significant differences between control and CM-treated groups.

\section{Discussion}

This study provides the first evidence that CM extract has antibladder cancer activity via extrinsic apoptosis pathway (Figure 2) and reduces mouse bladder tumor size using intravesical therapy (Figure 4). In addition to the therapeutic effect, CM also shows a good distinctive effect between normal bladder and cancer cells (Figure 1). After mouse intravesical therapy for 5 times, there is no harm by physiological observation and no damage to liver and kidney by blood biochemical parameter analysis (Table 1). This data suggest that $\mathrm{CM}$ extract might provide an alternative therapeutic agent for bladder cancer.

The aqueous extract of Paeonia suffruticosa has been reported to inhibit renal cancer cell invasion and metastasis via VEGFR-3 suppression [15]. In this study, we also prove that CM extract has anti-invasion effect in 5637 cells (Figure 3). Some bioactive anticancer compounds have been identified from Paeonia suffruticosa. For example, paeonol 

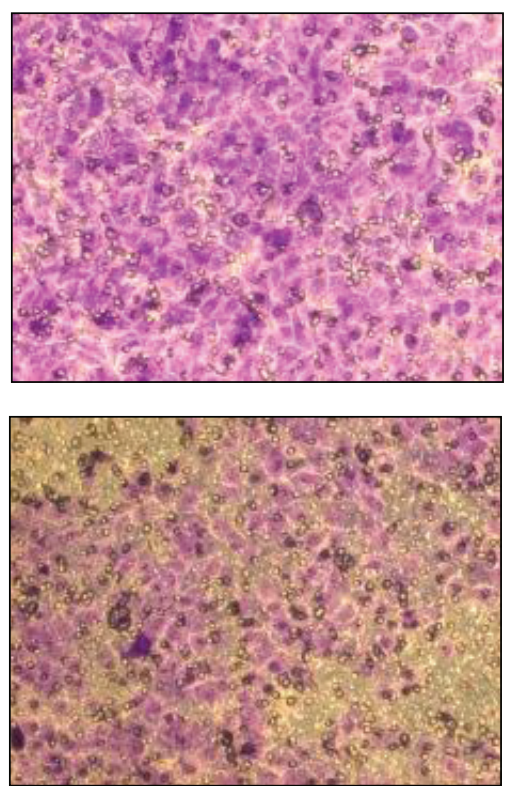

2
0.5
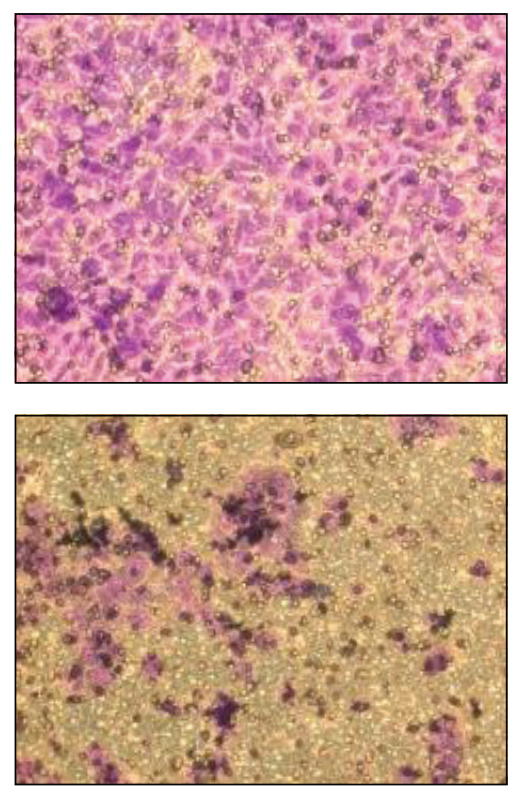

3
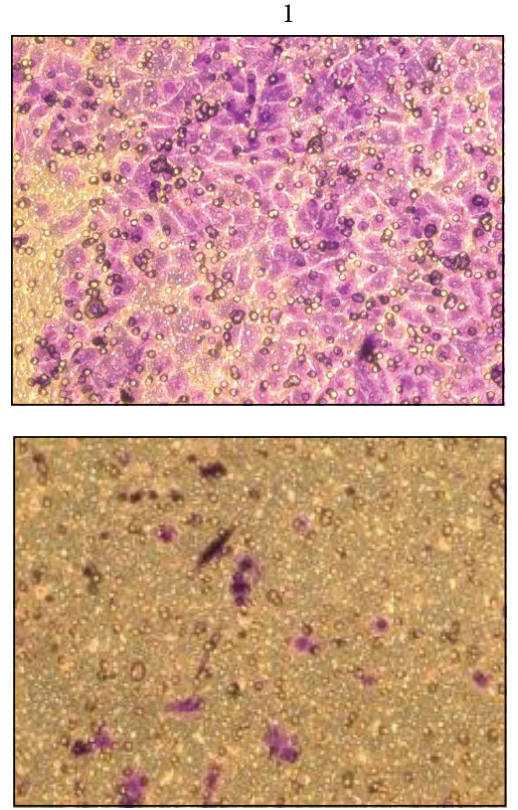

3.5

$\mathrm{CM}(\mathrm{mg} / \mathrm{mL})$

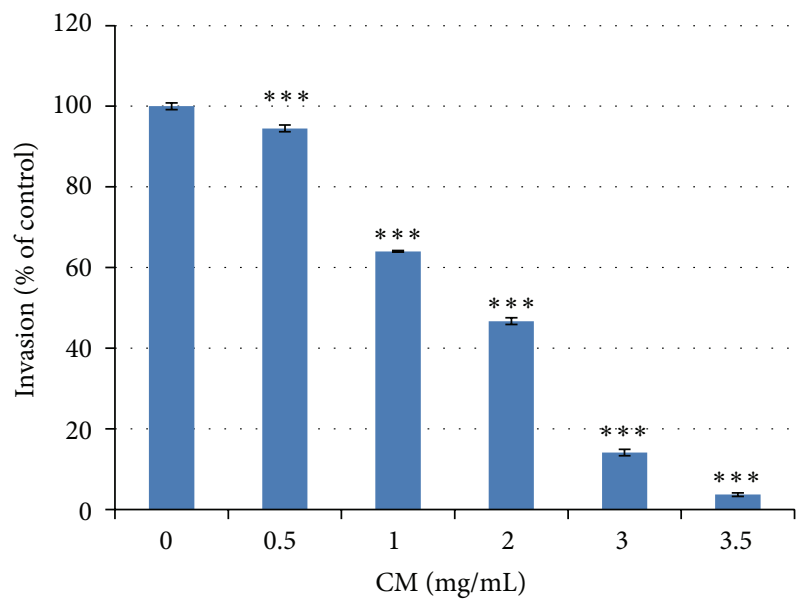

Figure 3: CM extract inhibits cell invasion. After medium or CM treatment for $24 \mathrm{~h}$, migrated 5637 cells were counted. The cell number of control was regarded as $100 \%$. Data represent the mean \pm SEM of triplicate. ${ }^{* * *} P<0.001$ compared with control. The experiment was repeated for three times.

has anticancer activity in esophageal cancer cells [26] and liver cancer cells [27]; paeoniflorin inhibits lung cancer cells growth via apoptotic cell death [18]. In addition to these two compounds, there are 50 compounds found in $50 \%(\mathrm{v} / \mathrm{v})$ methanol extract of Paeonia suffruticosa including 17 monoterpenes, 14 galloyl glucose, 10 acetophenones, 5 phenolic acids, 3 flavonoids, and 1 triterpene [28]. The active compound(s) for antibladder cancer activity need be investigated in the future. In this study, CM extract induces extrinsic apoptosis to cause caspase- 8 activation and cell death (Figure 2(c)). This phenomenon is also reported by other reports. The ethanol extract of Paeonia suffruticosa [17] and paeoniflorin [18] induce Fas/Fas ligand-mediated extrinsic apoptotic cell death.
Mouse orthotopic bladder tumor is a good model to mimic human bladder tumor and could be applied intravesically, which is the most widely used therapy for superficial bladder tumor [29]. In our previous studies, intravesical application of nature compound combretastatin A-4 also provides a good therapeutic effect but with some adverse events in blood parameters [23]; intraperitoneal baicalein shows a little effect in reducing bladder tumor size [25]. CM extract is the mixture of some bioactive compounds, but it shows a benefit in bladder cancer intravesical therapy. In conclusion, the present data elucidate the antibladder cancer effect of $\mathrm{CM}$ extract in vitro and in vivo and suggest that $\mathrm{CM}$ extract may provide an alternative therapeutic strategy for the intravesical treatment of superficial bladder cancer. 


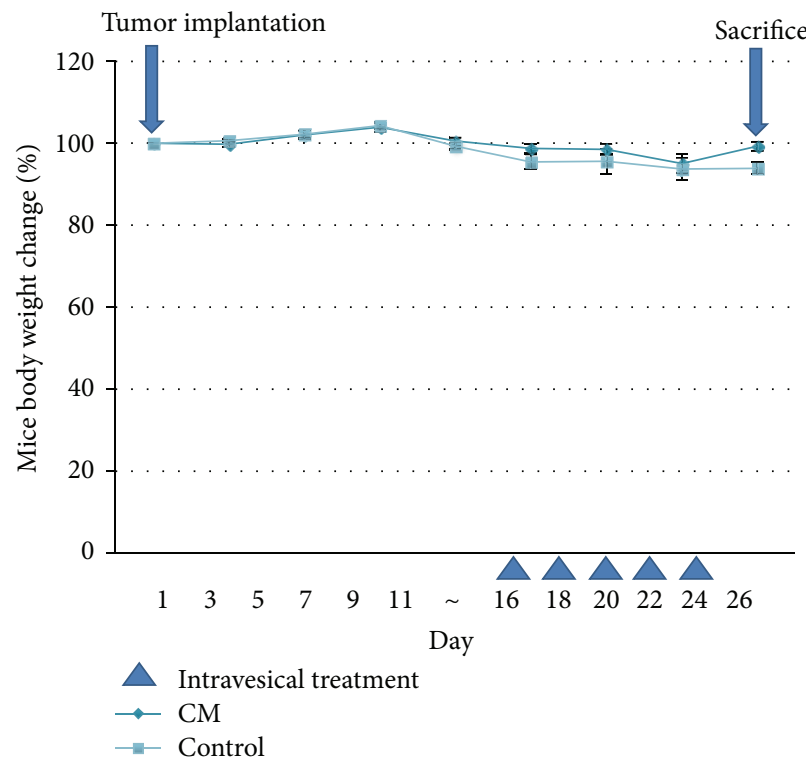

(a)
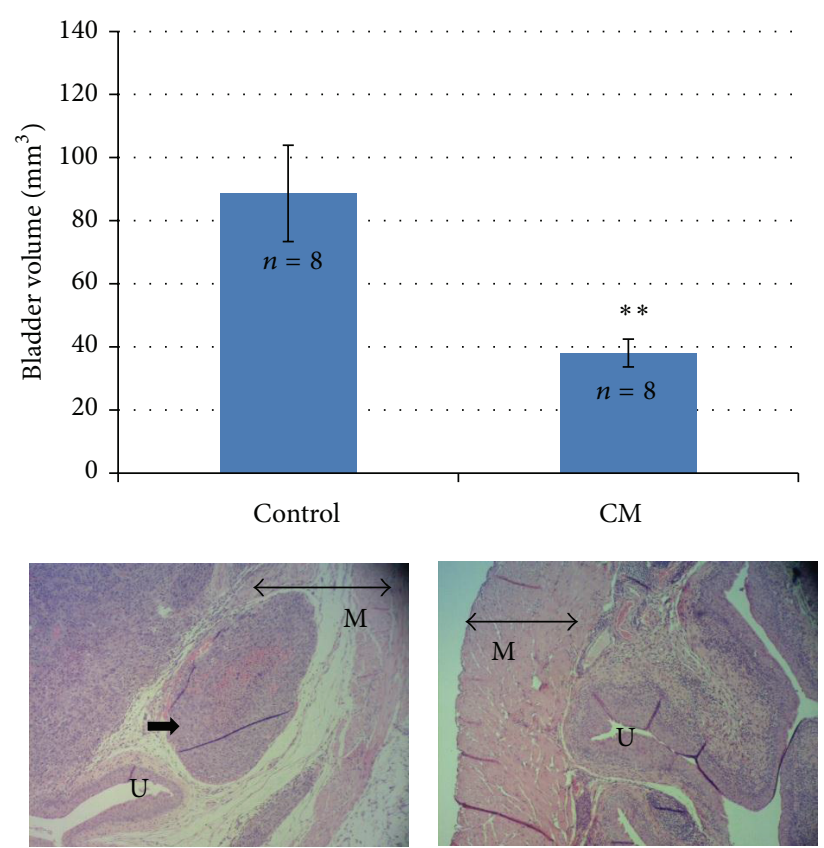

(b)

FIGURE 4: The antitumor effect of CM extract in a mouse orthotopic bladder tumor model. (a) Mouse body weight and drug schedule. MB49 cells were implanted at Day 1. Mouse body weight was recorded weekly or every operation. (b) Intravesical application of CM extract retards mouse bladder tumor growth and muscle invasion. After tumor implantation, CM extract was applied intravesically for 5 times. After sacrifice, each bladder volume $\left(\mathrm{mm}^{3}\right)$ was calculated by $\left(\right.$ length $\times$ wide $\left.{ }^{2}\right) / 2$. Data represent the mean \pm SEM. ${ }^{* *} P<0.01$ compared with control. In the HE stain slide photos, M: muscle, U: urothelium, double-head arrow: muscle layer, and single arrow in control: the tumor invading into muscle layer.

\section{Abbreviations}

BCG: Bacillus Calmette-Guérin

CM: $\quad$ Cortex Moutan

FBS: $\quad$ Fetal bovine serum

GAPDH: Glyceraldehyde-3-phosphate dehydrogenase

PARP: Poly(ADP-ribose) polymerase

TCC: Transitional cell carcinoma

TCM: Traditional Chinese Medicine

VEGFR: Vascular endothelial growth factor receptor.

\section{Conflict of Interests}

The authors declare that there is no conflict of interests.

\section{Acknowledgments}

This work was supported by grants from the National Science Council NSC101-2320-B-415-002-MY3 of Taiwan and from the Chiayi Christian Hospital R102-14 and R100-2, Taiwan.

\section{References}

[1] S. Tatsumi, T. Mabuchi, T. Abe, L. Xu, T. Minami, and S. Ito, "Analgesic effect of extracts of Chinese medicinal herbs Moutan cortex and Coicis semen on neuropathic pain in mice," Neuroscience Letters, vol. 370, no. 2-3, pp. 130-134, 2004.
[2] A. Hirai, T. Terano, and T. Hamazaki, "Studies on the mechanism of antiaggregatory effect of Moutan Cortex," Thrombosis Research, vol. 31, no. 1, pp. 29-40, 1983.

[3] H. C. Lin, H. Y. Ding, F. N. Ko, C. Teng, and Y. Wu, "Aggregation inhibitory activity of minor acetophenones from Paeonia species," Planta Medica, vol. 65, no. 7, pp. 595-599, 1999.

[4] M. Yoshikawa, T. Ohta, A. Kawaguchi, and H. Matsuda, "Bioactive constituents of chinese natural medicines. V. Radical scavenging effect of Moutan Cortex. (1): absolute stereostructures of two monoterpenes, paeonisuffrone and paeonisuffral," Chemical and Pharmaceutical Bulletin, vol. 48, no. 9, pp. 1327$1331,2000$.

[5] C. H. Lau, C. M. Chan, Y. W. Chan et al., "Pharmacological investigations of the anti-diabetic effect of Cortex Moutan and its active component paeonol," Phytomedicine, vol. 14, no. 11, pp. 778-784, 2007.

[6] J. Zhou, L. Zhou, D. Hou, J. Tang, J. Sun, and S. C. Bondy, "Paeonol increases levels of cortical cytochrome oxidase and vascular actin and improves behavior in a rat model of Alzheimer's disease," Brain Research, vol. 1388, pp. 141-147, 2011.

[7] H. Fujiwara, M. Tabuchi, T. Yamaguchi et al., "A traditional medicinal herb Paeonia suffruticosa and its active constituent 1,2,3,4,6-penta-O-galloyl-beta-d-glucopyranose have potent anti-aggregation effects on Alzheimer's amyloid beta proteins in vitro and in vivo," Journal of Neurochemistry, vol. 109, no. 6, pp. 1648-1657, 2009.

[8] H. S. Kim, A. Kim, J. M. Lee et al., "A mixture of Trachelospermi caulis and Moutan cortex radicis extracts suppresses collageninduced arthritis in mice by inhibiting NF- $\kappa$ B and AP-1," Journal 
of Pharmacy and Pharmacology, vol. 64, no. 3, pp. 420-429, 2012.

[9] T. C. Chou, "Anti-inflammatory and analgesic effects of paeonol in carrageenan-evoked thermal hyperalgesia," British Journal of Pharmacology, vol. 139, no. 6, pp. 1146-1152, 2003.

[10] M. Wu and Z. Gu, "Screening of bioactive compounds from Moutan Cortex and their anti-inflammatory activities in rat synoviocytes," Evidence-based Complementary and Alternative Medicine, vol. 6, no. 1, pp. 57-63, 2009.

[11] G. Li, C. S. Seo, K. S. Lee et al., "Protective constituents against sepsis in mice from the root cortex of Paeonia suffruticosa," Archives of Pharmacal Research, vol. 27, no. 11, pp. 1123-1126, 2004.

[12] C. L. Hsieh, C. Y. Cheng, T. H. Tsai et al., "Paeonol reduced cerebral infarction involving the superoxide anion and microglia activation in ischemia-reperfusion injured rats," Journal of Ethnopharmacology, vol. 106, no. 2, pp. 208-215, 2006.

[13] T. K. Au, T. L. Lam, T. B. Ng, W. P. Fong, and D. C. C. Wan, "A comparison of HIV-1 integrase inhibition by aqueous and methanol extracts of Chinese medicinal herbs," Life Sciences, vol. 68, no. 14, pp. 1687-1694, 2001.

[14] C. Y. Hsiang, C. L. Hsieh, S. L. Wu, L. Lu, T. Lai, and H. Ho, "Inhibitory effect of anti-pyretic and anti-inflammatory herbs on herpes simplex virus replication," American Journal of Chinese Medicine, vol. 29, no. 3-4, pp. 459-467, 2001.

[15] S. C. Wang, S. W. Tang, S. H. Lam et al., "Aqueous extract of Paeonia suffruticosa inhibits migration and metastasis of renal cell carcinoma cells via suppressing VEGFR-3 pathway," Evidence-Based Complementary and Alternative Medicine, vol. 2012, Article ID 409823, 9 pages, 2012.

[16] G. Xing, Z. Zhang, J. Liu, H. Hu, and N. Sugiura, "Antitumor effect of extracts from moutan cortex on DLD-1 human colon cancer cells in vitro," Molecular Medicine Reports, vol. 3, no. 1, pp. 57-61, 2010.

[17] H. S. Choi, H. S. Seo, J. H. Kim et al., "Ethanol extract of Paeonia suffruticosa Andrews (PSE) induced AGS human gastric cancer cell apoptosis via fas-dependent apoptosis and MDM2-p53 pathways," Journal of Biomedical Science, vol. 19, no. 1, p. 82, 2012.

[18] J. Y. Hung, C. J. Yang, Y. M. Tsai, H. Huang, and M. Huang, "Antiproliferative activity of paeoniflorin is through cell cycle arrest and the Fas/Fas ligand-mediated apoptotic pathway in human non-small cell lung cancer A549 cells," Clinical and Experimental Pharmacology and Physiology, vol. 35, no. 2, pp. 141-147, 2008.

[19] D. M. Parkin, "The global burden of urinary bladder cancer," Scandinavian Journal of Urology and Nephrology, no. 218, pp. 1220, 2008.

[20] A. F. Kantor, P. Hartge, R. N. Hoover, and J. F. Fraumeni Jr., "Familial and environmental interactions in bladder cancer risk," International Journal of Cancer, vol. 35, no. 6, pp. 703-706, 1985.

[21] M. Babjuk, W. Oosterlinck, R. Sylvester et al., "EAU guidelines on non-muscle-invasive urothelial carcinoma of the bladder, the 2011 update," European Urology, vol. 59, no. 6, pp. 997-1008, 2011.

[22] M. Manoharan, "Intravesical therapy for urothelial carcinoma of the bladder," Indian Journal of Urology, vol. 27, no. 2, pp. 252261, 2011.

[23] C. H. Shen, J. J. Shee, J. Y. Wu, Y. Lin, J. Wu, and Y. Liu, “Combretastatin A-4 inhibits cell growth and metastasis in bladder cancer cells and retards tumour growth in a murine orthotopic bladder tumour model," British Journal of Pharmacology, vol. 160, no. 8, pp. 2008-2027, 2010.

[24] S. Y. Wu, Y. R. Lee, C. C. Huang et al., "Curcumin-induced heme oxygenase-1 expression plays a negative role for its anti-cancer effect in bladder cancers," Food and Chemical Toxicology, vol. 50, no. 10, pp. 3530-3536, 2012.

[25] J.-Y. Wu, K.-W. Tsai, Y.-Z. Li et al., "Anti-bladder-tumor effect of Baicalein from Scutellaria baicalensis Georgi and its application in vivo," Evidence-Based Complementary and Alternative Medicine, vol. 2013, Article ID 579751, 12 pages, 2013.

[26] G. P. Sun, X. Wan, S. P. Xu, H. Wang, S.-H. Liu, and Z.-G. Wang, "Antiproliferation and apoptosis induction of paeonol in human esophageal cancer cell lines," Diseases of the Esophagus, vol. 21, no. 8, pp. 723-729, 2008.

[27] S. P. Xu, G. P. Sun, Y. X. Shen, W. Wei, W. Peng, and H. Wang, "Antiproliferation and apoptosis induction of paenol in HepG2 cells," World Journal of Gastroenterology, vol. 13, no. 2, pp. 250256, 2007.

[28] S. J. Xu, L. Yang, X. Zeng, M. Zhang, and Z. Wang, "Characterization of compounds in the Chinese herbal drug Mu-Dan-Pi by liquid chromatography coupled to electrospray ionization mass spectrometry," Rapid Communications in Mass Spectrometry, vol. 20, no. 22, pp. 3275-3288, 2006.

[29] D. A. Barocas and P. E. Clark, "Bladder cancer," Current Opinion in Oncology, vol. 20, no. 3, pp. 307-314, 2008. 


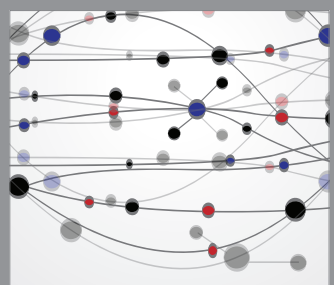

The Scientific World Journal
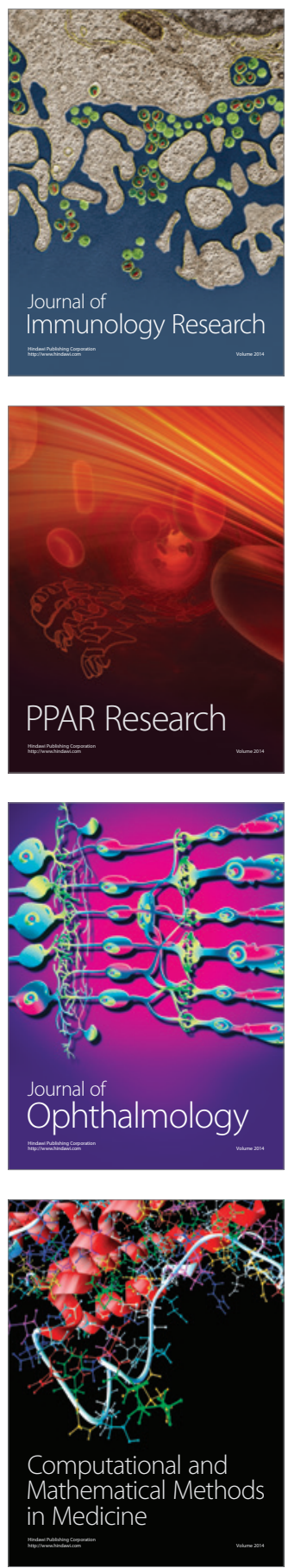

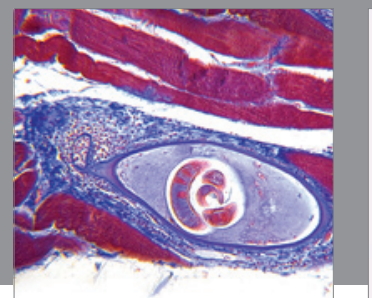

Gastroenterology

Research and Practice
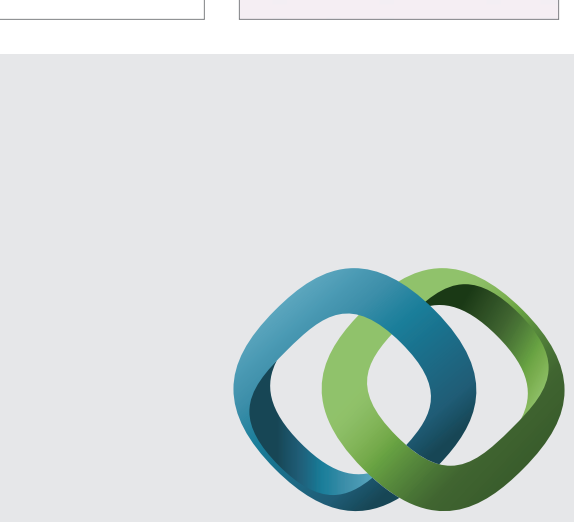

\section{Hindawi}

Submit your manuscripts at

http://www.hindawi.com
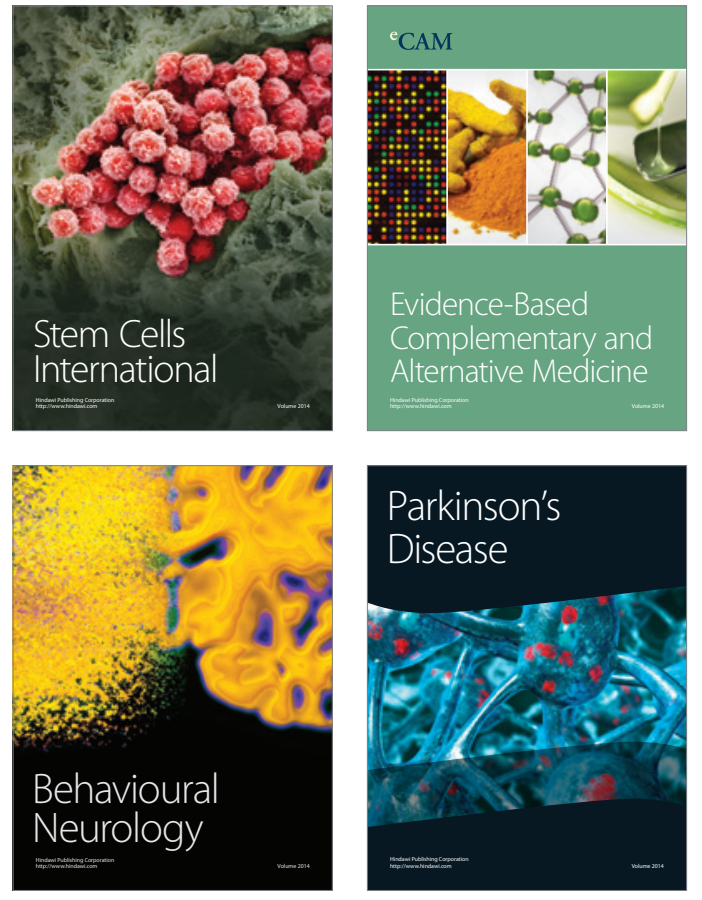
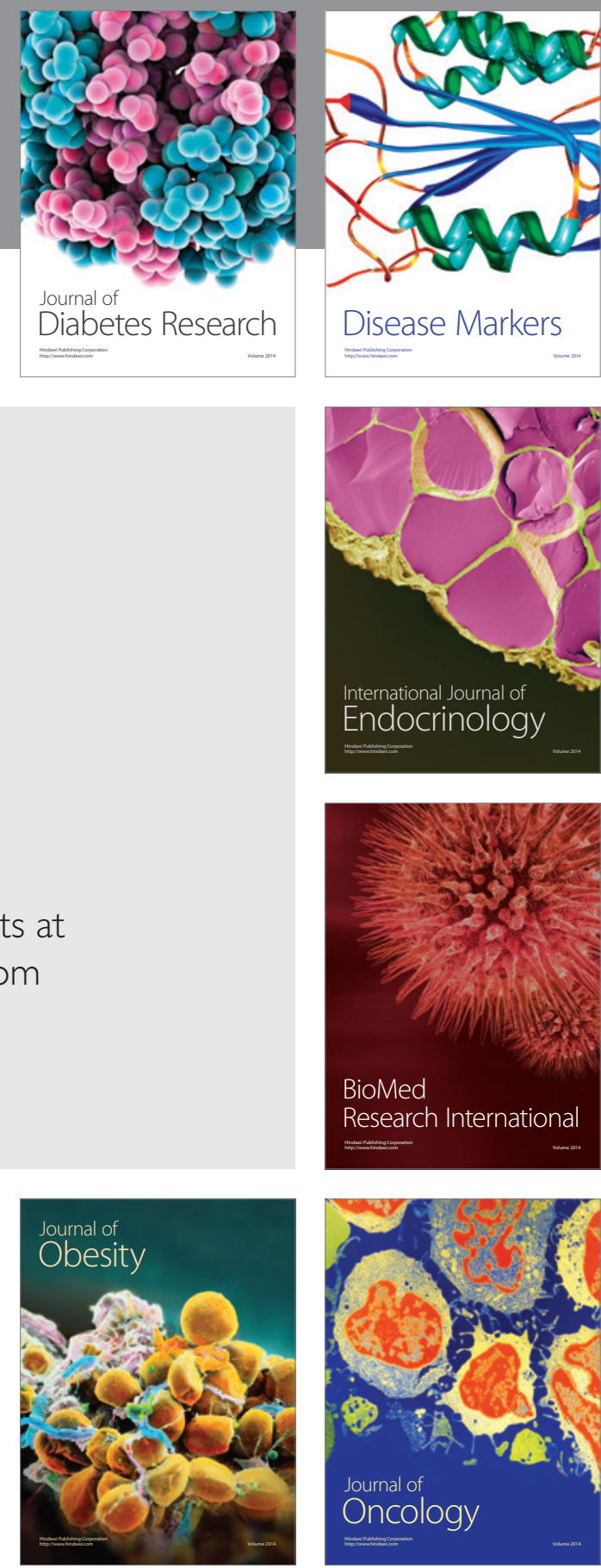

Disease Markers
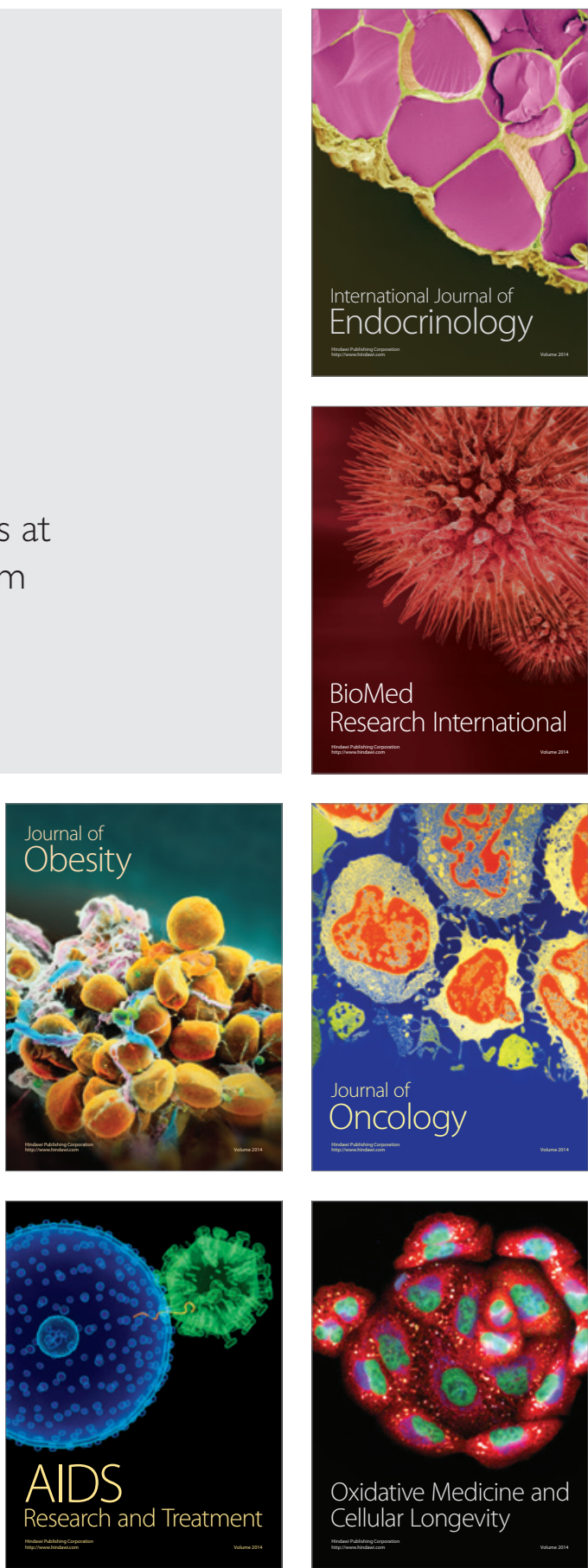